to a serotoninergic antidepressant such as fluvoxamine than do depressive patients without an underlying compulsive personality. This is important as the personality of a depressive patient can easily be assessed for orientation with a selective type of compound. In the past many studies have tried to predict treatment response to selective antidepressants by using biological markers such as the concentration of neurotransmitter metabolites in urine or cerebrospinal fluid, with controversial results. ${ }^{2}$ Moreover, these methods entail elaborate techniques for collecting body fluids and for assay.

Finally, our finding that depressive patients with a compulsive personality respond better to a serotoninergic antidepressant suggests some biochemical similarity in central serotonin disturbance between this subtype of depression and obsessive-compulsive disorder.

1 Jenike MA. Drug treatment of obsessive-compulsive disorder. In: Jenike MA, Baer L, Minichiello WE, eds. Obsessive-compulsive disorders: theory and management. 2nd ed. Littleton, Mass: Year Book Medical Publishers, 1990:100-12.

2 Joyce PR, Paykel ES. Predictors of drug response in depression. Arch Gen Psychiatry 1989;41:89-99.

American Psychiatric Association. Diagnostic and statistical manual of mental disorders, third edition. Washington, DC: APA, 1980

. Whard A Fluvoxamine A review of is pharmacodynamic and pharmacokinetic properties, and therapeutic efficacy in depressive illness. Drugs 1986;32:313-34

5 Thase ME, Hersen M, Bellack AS, Himmelhoch JM, Kupfer DJ. Validation of a Hamilton subscale for endogenomorphic depression. f Affective Disord 1983;5:267-78.

(Accepted 4 fuly 1991)

\title{
Doctors and drops
}

\section{G Gallagher, I Mackay}

Charing Cross Hospital, London

G Gallagher, FRCS, honorary senior registrar

I Mackay, FRCS, consultant

ENT surgeon

Correspondence to:

Dr G Gallagher, ENT

Department, Royal Victoria

Hospital, Belfast BT12,

Northern Ireland.

BMF 1991;303:761
Nasal drops are a popular method of drug delivery to the mucocolumnar epithelium of the nose. Drugs from sympathomimetics to steroids have been given in this way. Though insufflation by a metered spray has become available, nasal drops properly applied in the head down and forward position (Moffat's position) have proved more effective in treating disease arising in the osteomeatal complex. 'As our understanding of the key role of this complex in sinus disease increases, ${ }^{2}$ so the rationale for using nasal drops has been reasserted.

Treatment regimens usually prescribe a set number of drops to each nostril, to be self administered by the patient. The assumption is that a standard dose of the drug will thus be delivered. Many patients, however, have difficulty in sensing how many drops have entered the nose. Clearly, if the therapeutic margin of the drug is narrow safety margins may be exceeded.

Betamethasone sodium phosphate is a steroid preparation used in nasal disease. It is normally prescribed as two drops twice or three times daily in each nostril with the patient in Moffat's position. The proprietary product Betnesol (Glaxo Pharmaceuticals) utilises a standard dropper nozzle mechanism that is common to all current dropper products. It is designed to provide a constant size drop. To assess the accuracy of this system we recruited a group of healthy well informed doctors as volunteers.

\section{Subjects, methods, and results}

Ten asymptomatic doctors took part. All knew of the potential side effects of betamethasone and agreed to be rigorous in the application of the drops. A preweighed proprietary bottle of the drug (Betnesol) was given to each volunteer with the instructions to instil two drops into each nostril twice a day while adopting Moffat's position. Each administration was recorded. After 14 days the records were checked, the bottles reweighed, and the total weight of drug used by each volunteer thus calculated.

Manufacturer's data describe a standard drop weight of $0.025 \mathrm{mg}$ betamethasone solution. To corroborate this 10 drops formed under gravity from each of five proprietary bottles were weighed, and the average weight of the 50 drops was indeed $0.025 \mathrm{mg}$. Using these data we calculated the notional average drops used daily by each volunteer (table). All 10 volunteers overused the drug, by a range of $41-338 \%$ (mean $132 \%$ ). Seven volunteers reported difficulties in sensing the number of drops entering the nose.

To help further explain the overuse we examined the mechanism of drop formation. Whereas first drops under gravity formed promptly, second drops took up to three minutes to form and the tendency was to squeeze the bottle. When 50 drops from five bottles were formed by gentle squeezing the average weight was $0.033 \mathrm{mg}$, an increase over gravity drops of $32 \%$.

Total weight of drug used and average number of drops used daily by 10 volunteers using betamethasone nasal drops for 14 days

\begin{tabular}{lcc}
\hline Volunteer No & $\begin{array}{c}\text { Total weight of } \\
\text { drug used (mg) } \\
\text { (notional=2.8 mg) }\end{array}$ & $\begin{array}{c}\text { Average No of drops daily } \\
\text { (notional = 8) }\end{array}$ \\
\hline 1 & $7 \cdot 98$ & $20 \cdot 4$ \\
2 & $10 \cdot 14$ & $25 \cdot 8$ \\
3 & $6 \cdot 37$ & $16 \cdot 2$ \\
4 & $13 \cdot 75$ & $35 \cdot 1$ \\
5 & $4 \cdot 43$ & $11 \cdot 3$ \\
6 & $5 \cdot 74$ & $14 \cdot 6$ \\
7 & $6 \cdot 56$ & $18 \cdot 7$ \\
8 & $6 \cdot 16$ & $15 \cdot 7$ \\
9 & $5 \cdot 05$ & $12 \cdot 9$ \\
10 & $5 \cdot 92$ & $15 \cdot 1$ \\
\hline
\end{tabular}

\section{Comment}

Given a well informed, asymptomatic group of medical volunteers, drug overuse was the rule. As there was no bias towards overuse to alleviate symptoms the variability of results can be attributed to the mechanism of drug delivery. It was clear from the comments of the participants that accurate sensory assessment of the number of drops instilled was difficult. The inclination was to continue in the delivery position until drops were felt in the nose. In addition, the tendency to squeeze the bottle can greatly increase the dose delivered. When properly administered in Moffat's position drop solutions are stil superior to other methods of drug delivery in the treatment of nasal disease. Nevertheless, if the drug delivery system of a systemically active drug can be so insensitive and variable, then development of a more accurate system seems desirable.

1 Chalton R, Mackay I, Wilson R, Cole P. Double blind placebo controlled tria of betamethasone nasal drops for nasal polyposis. BMF 1985;291:788.

2 Stammberger $\mathrm{H}$. Endoscopic endonasal surgery - concepts in treatment of recurring rhinosinusitis. Part 1. Anatomic and pathophysiologic considerations. Otolaryngol Head Neck Surg 1986;94(2):143-6.

(Accepted 17 May 199l) 